\title{
Uma abordagem historiográfica e econômica sobre a ideia de progresso e sua relação com o bem-estar
}

A historiographical and economic approach on the idea of progress and its relationship with well-being

Un enfoque historiográfico y económico sobre la idea de progreso y su relación con el bienestar

Une approche historiographique et économique de l'idée de progrès et de son rapport au bien-être

\section{Pedro Henrique de Morais Campetti}

\section{CpenEdition}

Journals

Edição electrónica

URL: http://journals.openedition.org/espacoeconomia/17272

DOI: 10.4000/espacoeconomia. 17272

ISSN: 2317-7837

Editora

Núcleo de Pesquisa Espaço \& Economia

Refêrencia eletrónica

Pedro Henrique de Morais Campetti, « Uma abordagem historiográfica e econômica sobre a ideia de progresso e sua relação com o bem-estar », Espaço e Economia [Online], 19 | 2020, posto online no dia 03 setembro 2020, consultado o 10 setembro 2020. URL : http://journals.openedition.org/ espacoeconomia/17272 ; DOI : https://doi.org/10.4000/espacoeconomia.17272

Este documento foi criado de forma automática no dia 10 setembro 2020.

(c) NUPEE 


\title{
Uma abordagem historiográfica e econômica sobre a ideia de progresso e sua relação com o bem- estar
}

\author{
A historiographical and economic approach on the idea of progress and its \\ relationship with well-being \\ Un enfoque historiográfico y económico sobre la idea de progreso y su relación \\ con el bienestar
}

Une approche historiographique et économique de l'idée de progrès et de son rapport au bien-être

Pedro Henrique de Morais Campetti

\section{NOTA DO AUTOR}

Nota de redação: "Esse trabalho recebeu fomento e apoio institucional do IFRS. Registro aqui meu agradecimento."

INTRODUÇÃo

2 O Progresso de uma nação ou dos indivíduos tem sido conceituado em uma variedade de formas e sentidos em diferentes épocas, dependendo dos regimes políticos vigentes, influências culturais e as condições ambientais. Entretanto, a ideia de progresso está intimamente relacionada com uma noção ampla de bem-estar e também com as mudanças ocorridas em um país ou região ao longo do tempo (HALL et al., 2010). 
3 Bem-estar é um conceito usado para se referir às condições, situação ou estado de vida de uma pessoa. Para identificar tal situação, uma variedade de termos diferentes tem sido utilizada na literatura, sendo os mais comuns: qualidade de vida, padrão de vida e desenvolvimento humano. Outros incluem utilidade, prosperidade, satisfação das necessidades, expansão das capacidades, redução da pobreza e felicidade (MCGILLIVRAY, 2007; CONCEIÇÃO; BANDURA, 2008).

4 Apesar de haver outros conceitos de progresso, questões estas que são abordados nas seções que seguem, o entendimento utilizado neste trabalho relaciona o progresso como o estado atual ou as mudanças ocorridas na situação de vida dos indivíduos de uma determinada região ou país, isto é, no seu bem-estar. Ou seja, neste caso o progresso é um conceito que é necessariamente satisfeito quando ocorre o bem-estar dos indivíduos, compreendendo também o bem-estar das gerações futuras.

5 Sendo assim, este artigo tem por objetivo fazer uma revisão bibliográfica sobre os conceitos de progresso e de bem-estar através de uma perspectiva historiográfica e econômica. Também procura analisar quais são as medidas econômicas, sociais, ambientais, ou mesmo multidimensionais, utilizadas para avaliação da situação da sociedade ou de uma certa região. Tal discussão é apresentada de modo cronológico e conceitual. Inicialmente são explorados os conceitos, começando pelo constructo Progresso (seção 2), bem como uma crítica a este conceito (seção 3), para em seguida tratar de Bem-Estar (seção 4). Por último, são discutidas as medidas tradicionais (seção 5) e hodiernas (seção 6) do progresso.

\section{A IDEIA DE PROGRESSO}

6 Autores que tratam sobre o tema progresso, costumam se referir a este como uma ideia - a ideia de progresso. Eles não explicam a etimologia ou as razões pelas quais utilizam esta palavra. Entretanto, parece que isto está ligado ao fato de crerem no progresso como um dogma, que, de algum modo, esteve presente em toda a História humana (cf. ABBAGNANO, 2000; DUPAS, 2006; NISBET, 1980). Tanto é que Nisbet afirma que a ideia de progresso está intrinsecamente relacionada às motivações, impulsos, desejos, incentivos os quais tem fundamentado os mais extraordinários feitos da civilização:

a história de tudo que de mais importante existe no Ocidente - religião, ciência, razão, liberdade, igualdade, justiça, filosofia, as artes, e assim por diante - está profundamente ancorada na crença de que o que realizamos em nossa época é, ao mesmo tempo, um tributo à grandeza do passado e ao fato dele ser indispensável, devendo-se também à confiança num futuro ainda mais radioso. (NISBET, 1980, p. 20)

Esta confiança em um futuro mais glorioso é também um dos conceitos de progresso tratados por Abbagnano (2000), Dupas (2006), Nisbet (1980) e Outhwaite e Bottomore (1996), isto é "a crença de que os acontecimentos históricos desenvolvam-se no sentido mais desejável, realizando um aperfeiçoamento crescente" (ABBAGNANO, 2000, p. 799), ou a confiança de "que a civilização se mova para uma direção entendida como benévola ou que conduza a um maior número de existências felizes" (DUPAS, 2006, p. 30), ideia está encastelada "(...) no anseio universal de uma marcha para a utopia" (ibid., p. 22). Nisbet também trata o conceito de progresso como um elemento essencial do movimento histórico, e que compreende passado, presente e futuro. Para ele, o progresso é uma espécie de axioma que sustenta a evolução e o desenvolvimento da civilização, de modo que parafraseia J. B. Burry, ao propor que “(...) a idéia de progresso 
acredita que a humanidade avançou do passado - a partir de alguma condição original de primitivismo, barbárie, ou até nulidade - continua agora avançando e deverá ainda avançar através do futuro que possa ser previsto" (NISBET, 1980, p. 16-17).

8 Todavia, dos autores citado, Nisbet é o único que acredita que esta forma de entendimento do progresso - como sendo um ideal em vistas de um futuro melhor estivesse presente desde a Antiguidade. Ele cita então as origens desta ideia nos mitos contados pelo poeta grego Hesíodo (entre 750-650 a.c) (NISBET, 1980). Os demais autores consideram que o progresso, ao menos até o século XVII, era entendido simplesmente como sendo uma melhora qualquer em determinada aérea, ciência, técnica (cf. ABBAGNANO, 2000; DUPAS, 2006; OUTHWAITE; BOTTOMORE, 1996). Quer dizer, os eventos se desenvolveriam num sentido desejável, como, por exemplo, o progresso da física, ou o progresso da agricultura, de modo que isto não constituía uma crença no futuro. Para estes autores, a primeira enunciação de progresso como ideia e ideal teria surgido através de Francis Bacon:

do mesmo modo como de um homem idoso podemos esperar um conhecimento muito maior das coisas humanas e um juízo mais maduro que o de um jovem, graças à experiência e ao grande número de coisas que viu, ouviu e pensou, também da nossa era (...) seria justo esperarmos muito mais coisas que dos tempos antigos, pois esta é a maioridade do mundo, em que ele está enriquecido por inúmeras experimentações e observações. (FRANCIS BACON, 1620 apud ABBAGNANO, 2000, p. 799)

9 Após isto, o progresso também passou a ser assimilado a outras doutrinas, como se estivessem intimamente relacionadas. Quer dizer, os dois conceitos de progresso apresentados anteriormente não mudaram, o que ocorre é que algumas teorias ou pensamentos ganharam destaque, no sentido de serem norteadoras do progresso humano. Por exemplo, o iluminismo relacionou o progresso aos ideais de liberdade, enquanto que com a revolução industrial, o mesmo passou a estar ligado à prosperidade econômica. E, além disto, outras concepções de progresso emergiram através de diferentes expoentes do pensamento Ocidental, como o desenvolvimento da ordem [Augusto Comte, 1798-1857], a evolução das espécies [Charles Darwin, 1809-1882], o fim da burguesia [Karl Marx, 1818-1883], a superação das pulsões instintivas [Sigmund Freud, 1856-1939], a destruição criativa [Joseph Schumpeter, 1883-1950], entre outros (DUPAS, 2007).

10 Sendo assim, pode-se sintetizar os conceitos do progresso através de duas abordagens: significa simplesmente uma melhora qualquer em determinada aérea, ciência, técnica etc.; ou então um impulso inerente aos homens em vista de um futuro mais glorioso (cf. ABBAGNANO, 2000; DUPAS, 2006; NISBET, 1980; OUTHWAITE; BOTTOMORE, 1996). Além disso, aproximações a ideias de progresso têm sido feitas em uma variedade de formas e sentidos em diferentes épocas, dependendo dos regimes políticos vigentes, influências culturais e as condições ambientais (HALL et al., 2010). Uma destas tem ganhado destaque desde a revolução industrial até o século XX: a fé no crescimento econômico como propulsor do progresso, sendo que através do aumento da produtividade e do domínio da natureza seriam asseguradas condições de vida sempre mais confortáveis aos indivíduos (DUPAS, 2006).

11 Entretanto, existem contraposições à concepção econômica de progresso e à esperança de um futuro de bem-aventuranças, críticas estas que levaram a uma nova ideia, a partir do século XXI, que aproxima o progresso a uma noção ampla de bem-estar e à 
preocupação com a situação das próximas gerações. Estas questões são detalhadas na próxima subseção.

\section{O PROGRESSO COMO BEM-ESTAR}

12 Apesar dos saltos qualitativos da ciência e da tecnologia e dos avanços civilizatórios em toda a história humana, questionamentos e críticas tem sido feitos se a humanidade realmente tem avançado no rumo certo. Alguns pesquisadores do assunto, como Dupas (2006), Giannetti (2007), Outhwaite e Bottomore (1996) e Abbagnano (2000), concordam que ao deflagrar as duas Grandes Guerras e com o advento da bomba atômica, e seu uso em Nagasaki e Hiroshima, há um abalo substancial na crença no progresso. Nisbet (1980) também se apercebe da derrocada da ideia de progresso na última metade do século XX. Porém, ele afirma que a origem disso não está nas duas Guerras Mundiais, mas na erosão das premissas intelectuais e espirituais que deram suporte a esta fé ao longo da História.

13 Além disso, outros fatos corroboram com a descrença no progresso, e são concernentes a um mundo de contradições, no qual as conquistas da ciência e o aumento da riqueza coexistem com uma diversidade de problemas sociais e ambientais. De acordo com Amartya Sen (2010, p. 9), evidencia-se na última metade do século XX e início do século XXI um mundo de "opulências sem precedentes", mas igualmente de "privação, destituição e opressão extraordinárias", em que se apresentam "problemas novos convivendo com antigos". Stiglitz, Sen e Fitoussi (2009) alertam que o planeta se encontra diante de uma eminente crise ambiental, especialmente associada ao aquecimento global. Saches (2012) destaca o que chama de males da vida moderna como obesidade, tabagismo, diabetes, depressão, distúrbios alimentares, distúrbios psicossociais, vícios diversos, declínio da confiança social e crescimento dos níveis de ansiedade. Layard (2008) constata que os indivíduos não têm se declarado mais felizes nas últimas quatro ou cinco décadas nos Estados Unidos, Japão e Europa.

Igualmente pode-se citar Kahneman, Diener e Schwarz (1999), que contextualizam os paradoxos da contemporaneidade através de três argumentos: primeiro, há dúvidas se o crescimento econômico é suficiente para resolver os problemas sociais; Segundo, há o fato óbvio de que o crescimento econômico futuro se tornar mais difícil, se simultaneamente houver o interesse em evitar uma mudança climática desastrosa e; Terceiro, tem ocorrido o crescimento de uma nova ciência da Felicidade, que fornece provas concretas de que novas prioridades são necessárias para as sociedades atingirem níveis mais elevados de bem-estar.

15 Em razão de tais constatações, pode-se conjecturar que o progresso apresenta contradições inerentes a sua própria condição. Do mesmo modo que os estudos da física nuclear propiciaram a criação da bomba atômica, igualmente permitiram inovações na medicina. Outro exemplo, trazido por Dupas (2006, p. 183), está no problema da "medicalização da saúde e o abandono do doente em favor da doença". A saúde dos indivíduos parece subvertida ao interesse econômico da indústria farmacêutica, que inova com a criação de drogas diversificadas - e publicidade para incentivar o consumo destas. Sem dúvida, os medicamentos proporcionaram redução da mortalidade, porém verifica-se que muito se faz para o desenvolvimento de novos fármacos, mas pouco se investe em escala global "para prevenir doenças, como alimentos saudáveis, redução da contaminação ambiental e da emissão de ondas eletromagnéticas, redução da ansiedade e da tensão" (DUPAS, 2006, p. 177). 
16 Entretanto, estas contradições talvez sejam apenas aparentes. Nisbet (1980) adverte que o progresso não é apenas resultado dos avanços nas diversas áreas do conhecimento humano, mas também do aperfeiçoamento moral e espiritual do homem na terra. Neste sentido, verifica-se a ocorrência de um progresso do conhecimento nos últimos séculos, mas que não foi acompanhado por uma elevação da moral e das virtudes humanas.

17 De qualquer modo, as constatações apresentadas anteriormente abalam a ideia de progresso quando entendido como uma esperança para o futuro, questionando-se inclusive se em alguns casos seria melhor não ter progredido devido aos resultados contraproducentes de tal movimento. Diante disso, Dupas (2006) questiona se os indivíduos são mais felizes e sensatos por conta dos avanços do conhecimento e da tecnologia. Ele diz que, apesar do desejo por maior progresso, constata-se que obtê-lo não melhora necessariamente a qualidade de vida para a maioria das pessoas. Nesse sentido, a crítica ao ideal de progresso está no fato de as pessoas não se sentirem melhores ou mais felizes apesar do crescimento econômico e do avanço das ciências.

18 Nesta conjectura, nasce um novo entendimento de progresso: este ocorre quando há uma melhora no bem-estar dos indivíduos sem comprometer as gerações futuras, sendo este bem-estar entendido de modo amplo e não estritamente econômico. Ou seja, deve estar vinculado também a aspectos ambientais, sociais e subjetivos, bem como à capacidade dos indivíduos de realizarem seus projetos de vida (cf. HALL et al., 2010, SCRIVENS; IASIELLO, 2010; STIGLITZ; SEN; FITOUSSI, 2009; TREWIN; HALL, 2010). É este o entendimento utilizado neste trabalho.

19 Este conceito de progresso não exclui os apresentados anteriormente (com base em ABBAGNANO, 2000; DUPAS, 2006; NISBET, 1980), a diferença está no fato de sua especificidade, de avaliar o progresso como um fim, sendo este fim o bem-estar humano. Por exemplo, se o crescimento econômico for causado à custa da degradação ambiental, então não há progresso, ou, pelo menos, tal progresso econômico deverá ser relativizado em razão do regresso causado ao meio ambiente. Ou seja, esta ideia de progresso está intimamente relacionada com uma noção ampla de bem-estar e também com as mudanças ocorridas em um país ou região ao longo do tempo.

\section{APORTES TEÓRICOS SOBRE O BEM ESTAR}

20 O progresso pode ser compreendido sinteticamente como uma mudança para melhor. Como visto anteriormente, neste trabalho considera-se que a melhora seja concernente ao bem-estar dos indivíduos e das sociedades. Deve-se, para isto, olhar para o passado, de forma a comparar a situação presente com a pretérita, bem como olhar para o futuro, para avaliar se a manutenção do bem-estar é sustentável ao longo do tempo.

21 Se, neste estudo, o progresso é entendido como uma melhora do bem-estar dos indivíduos, faz-se necessário compreender o que é bem-estar. Dentre as teorias que tratam sobre o tema, três são as que mais se aproximam da perspectiva de progresso, são elas: a Economia Tradicional, a Economia da Felicidade e a Abordagem das Capacidades. A Economia Tradicional tem sido, como o próprio nome induz, a teoria dominante, sendo seus pressupostos utilizados para a formulação de políticas econômicas e medidas avaliativas (HUNT, 2005). Entretanto, a vertente que mais tem prosperado nas pesquisas dos últimos anos é a do bem-estar subjetivo ou, como é conhecida, a Economia da Felicidade, que tem utilizado do julgamento e apreciação das 
próprias pessoas quanto suas condições de vida (MCGILLIVRAY, 2007). Contudo, a conceituação de bem-estar mais influente é a Abordagem das Capacidades, em que a avaliação é feita em termos de capacidade para alcançar funcionamentos considerados valiosos (MCGILLIVRAY, 2007).

Também Stiglitz, Sen e Fitoussi (2009) trabalharam com estes três referenciais teóricas, pois consideram que através desta abordagem multidimensional do bem-estar faz-se possível uma compreensão mais ampla sobre o que realmente importa para as pessoas. Os autores explicam que cada uma delas fornece uma base de dados informacional capaz de ser utilizada para a formatação de um quadro referencial com indicadores para medição do progresso. Por exemplo, geralmente os indicadores utilizados respondem apenas parcialmente se o bem-estar das pessoas está melhorando ou não. Este é o caso do PIB, que é uma medida utilizada principalmente pela Economia Tradicional. O PIB se concentra exclusivamente sobre a produção econômica de bens e serviços, mas não leva em conta questões como a distribuição de renda, liberdade, as capacidades dos indivíduos para lograrem uma vida que valorizam, bem como a felicidade com a vida que levam, dados estes que o contributo da Economia da Felicidade e da Abordagem das Capacidades fornecem. Assim, uma explanação sobre o desenvolvimento de cada uma destas teorias está exposta no texto que segue.

Economia Tradicional, Ortodoxa, Neoclássica ou Mainstream são termos usados para referir-se a corrente teórica principal em Economia, pois é amplamente aceita e ensinada em universidades de destaque, em contraste com outras correntes denominadas heterodoxas. A origem desta linha tradicional está associada à economia neoclássica do final do século XIX e também à síntese neoclássica nos anos de 1930, as quais possuem por pressupostos éticos a filosofia utilitarista. (BLANCHARD, 2008; COLANDER, 2000; HUNT, 2005). Nesta abordagem, renda, riqueza e consumo passam a ser concebidas como medidas de bem-estar. "Because income correlates with number of choices, greater income is equivalent to higher well-being" (DIENER; SELIGMAN, 2004 , p. 2). E, consequentemente, métricas relativas ao crescimento do PIB, aumento da renda dos indivíduos, avanços tecnológicos, industrialização, costumam balizar o desenvolvimento de um país, de acordo com a teoria tradicional (SEN, 2010). É fato que existe uma distinção - iniciada através dos trabalhos de Paul Samuelson no final da década de 1940 - entre a parte dedicada à Microeconomia, discutida até o momento, e aquela cabível a Macroeconomia, e preocupada, entre outras coisas, com o desempenho do PIB (SANDRONI, 2004). Entretanto, existe também uma correlação entre as duas matérias pelo fato de que o aumento do PIB da nação (macro) consequentemente melhora as condições de renda dos indivíduos (micro), o que lhes permite aumentar o consumo. Como um pressuposto fundamental da análise econômica é que o bem-estar é aumentado através do consumo de bens e serviços, o PIB é então considerado por muitos como um critério de bem-estar e progresso (CONCEIÇÃO; BANDURA, 2008).

Por sua vez, a Economia da Felicidade avalia o bem-estar através da combinação de técnicas de economistas e psicólogos e se baseia em noções mais amplas de utilidade do que na Economia Tradicional. Na Economia da Felicidade, o bem-estar é compreendido através de aspectos subjetivos. O bem-estar subjetivo enfatiza a avaliação que os indivíduos fazem de suas próprias vidas, isto é, o quanto pensam e sentem que suas vidas estão indo bem (DIENER; SELIGMAN, 2004; GRAHAM, 2008). Entretanto, até recentemente, se uma pessoa dissesse estar feliz, os céticos diriam que é apenas um estado subjetivo, pois não havia meios para mostrar qualquer conteúdo objetivo. 
Porém, na atualidade, há critérios científicos estabelecidos e validados capazes de medir o bem-estar subjetivo dos indivíduos (LAYARD, 2008). Como consequência destes avanços, felicidade, para os economistas, geralmente não é definida, mas empiricamente mensurada (BRUNI; PORTA, 2007). Deste modo, em Economia da Felicidade tem-se utilizado a felicidade reportada como forma de analisar a composição do bem-estar dos indivíduos, o que também poderia ser utilizado como medida da utilidade. Ou seja, os economistas que utilizam estes dados retomam a ideia de que a utilidade das pessoas pode e deve ser mensurada, mas desta vez em termos de felicidade relatada (FREY; STUTZER, 2002). Assim, a Economia da Felicidade retoma o caráter central da felicidade para valoração da sociedade, sendo que os objetivos econômicos, políticos e sociais deveriam ser traçados de modo a aumentá-la. A felicidade é entendida então com fundamental para avaliação do bem-estar (LAYARD, 2008).

Por último, a abordagem das capacidades é uma estrutura teórica que envolve dois princípios normativos fundamentais: primeiro, a afirmação de que a liberdade de alcançar o bem-estar é de importância moral primária, e, segundo, que a liberdade para alcançar o bem-estar deve ser entendida em termos de capacidades dos indivíduos, isto é, as suas oportunidades reais para fazer e ser o que têm motivos para valorizar. Esta abordagem levou a uma literatura nova e interdisciplinar nas ciências sociais, resultando em novas estatísticas e indicadores sociais e em estudos sobre desenvolvimento econômico, desenvolvimento humano, dentre outros (ROBEYNS, 2011). A perspectiva teórica da abordagem das capacidades é geralmente concebida como uma estrutura flexível e polivalente, em vez de uma teoria precisa de bem-estar. Isso está em contraste com outros relatos de bem-estar, que se concentram exclusivamente em meios materiais como recursos, renda ou riqueza, ou em categorias subjetivas, como a felicidade (ROBEYNS, 2005; 2011). A concepção de bem-estar através da abordagem das capacidades pode ser compreendida elementarmente a partir de Sen (2008; 2010), que explica o bem-estar através de dois conceitos principais: funcionamentos e capacidades. Funcionamentos referem-se a estados (ser) ou ações (fazer), em outras palavras, refletem as várias coisas que um indivíduo considera valioso fazer ou ter. "Viver pode ser visto como consistindo num conjunto de 'funcionamentos' inter-relacionados [...]" (SEN, 2008, p. 79). Os funcionamentos podem variar de coisas elementares, como ter uma boa saúde e estar bem nutrido, até realizações mais complexas como tomar parte das atividades da comunidade, ser feliz e ter respeito próprio. Pode-se oferecer uma enormidade de exemplos, mas o importante aqui é que "[...] uma avaliação do bem-estar tem de assumir a forma de uma apreciação desses elementos constituintes" (SEN, 2008, p. 79), isto é, os funcionamentos realizados pelos indivíduos. Já as capacidades são concernentes às alternativas de funcionamentos cuja realização é factível. A capacidade, na perspectiva em questão, não possui o sentido ordinário do termo, como estar apto ou habilitado a fazer algo, mas significa as condições para realizar funcionamentos. Ou seja, a capacidade é um tipo de liberdade substantiva, pois reflete as oportunidades de escolha que o indivíduo tem de realizar aquilo que considera importante ou de valor. Segundo Sem, "[e]scolher pode em si ser uma parte valiosa de viver, e uma vida de escolhas genuínas com opções representativas pode ser concebida [...] como mais rica" (SEN, 2008, p. 81).

Deste modo, foi possível compreender os aspectos centrais das teorias em voga que tratam sobre bem-estar. Portanto, nas duas seções seguintes serão discutidas medidas 
tradicionais e hodiernas de progresso, sendo que em ambas há influência das questões e teorias abordadas anteriormente.

\section{MEDIDAS TRADICIONAIS DE PROGRESSO}

27 A ideia de quantificar aspectos críticos das sociedades, a fim de melhor compreender a sua situação, não é nova. Os governos coletam dados sobre a população e os recursos desde os tempos antigos. De acordo com Scrivens e Iasiello (2010), na Europa do século XVII foram feitas as primeiras tentativas de avaliação da riqueza da nação através de Sir William Petty, na Grã-Bretanha, e dos chamados Fisiocratas, na França. Entretanto, apenas no século XX, com o desenvolvimento de novos indicadores e coletas de dados, foi possível fazer uso de medidas concernentes a certas perspectivas de progresso social. No texto que segue é apresentada uma descrição de como foi tratada a questão de medir a situação da sociedade e como isso evoluiu para a incorporação de outras dimensões que possam captar o bem-estar.

28 A primeira iniciativa importante de mensuração e análise do estado econômico da sociedade trata-se das contas nacionais, que começaram a surgir a partir dos anos 1930, o que levou às primeiras estimativas detalhadas da riqueza de um país através das óticas do produto, da renda ou do dispêndio, e também o principal caminho para aferir o progresso de modo objetivo (HALL et al., 2010). Através da contabilidade nacional é possível apurar o Produto Interno Bruto (PIB) do país. O PIB tem sido o indicador mais empregado por pessoas, empresas e governos durante o século XX, pois fornece o valor de todos os bens e serviços produzidos dentro de uma entidade geográfica em dado período de tempo. Ao agregar a miríade de fontes de produção econômica de um país em um único número, o PIB fornece um meio poderoso para avaliar o progresso de uma nação, além de haver uma forte correlação entre diferentes níveis de PIB e importantes indicadores de bem-estar (SCRIVENS; IASIELLO, 2010).

29 A segunda tentativa de mensuração de aspectos concernentes ao bem-estar das sociedades refere-se ao desenvolvimento de indicadores sociais. A história das estatísticas sociais é bastante antiga, havendo exemplos desde o século XVII, quando John Graunt usou os dados da mortalidade em Londres para construir um quadro estatístico da saúde dos londrinos (PERLMAN; MCCANN Jr, 1998). Também no século XIX houve esforços nos EUA e na Europa para coleta e análise de dados sociais, buscando identificar correlação entre diferentes componentes como pobreza e doenças ou entre alcoolismo e crime (COBB; RIXFORD, 1998). Entretanto, é apenas após a década de 1960 que se verifica o aumento do interesse por indicadores sociais através de uma série de publicações tratando sobre questões como pobreza, relações raciais, desemprego, habitação, dentre os quais a revista Social Indicators Research e os relatórios da ONU (1975) e da OCDE (1982). Este último, por exemplo, possuía um compendio com 33 indicadores divididos em oito grandes temas, tendo por objetivo auxiliar os países membros da OCDE a medir o fenômeno social.

30 O terceiro cometimento visando avaliar aspectos da sociedade refere-se ao tema sustentabilidade e meio-ambiente. Este movimento iniciou na década de 1960 através da conscientização da opinião pública quanto à fragilidade do meio-ambiente, principalmente nos países desenvolvidos. Mas é na década de 1980 que ocorre aumento significativo na preocupação quanto à gravidade dos problemas ambientais e o apoio para a proteção do meio ambiente (DUNLAPA, 1991). Em razão disso, começaram a ser elaborados indicadores de sustentabilidade através de organizações como a ONU (1984), 
a OCDE (1991) e a União Europeia (CE, 2005; 2010). Além disso, Pintér, Hardi e Bartelmus (2005) contabilizaram que já foram elaborados ao menos 669 indicadores para o meioambiente. Um indicador que tem ganhado destaque é a Pegada Ecológica, que busca mostrar a quantidade de território (em hectares) que são necessários para sustentar os padrões de consumo de uma pessoa ou de toda uma sociedade (WWF, 2006).

31 A quarta tentativa de medir elementos concernentes ao bem-estar adveio do desenvolvimento de indicadores subjetivos. A abordagem subjetiva mede a qualidade de vida a partir da própria perspectiva e experiência do indivíduo (SCRIVENS; IASIELLO, 2010; CONCEIÇÃO; BANDURA, 2008). Neste sentido, são utilizados indicadores relacionados à satisfação de vida familiar, satisfação no trabalho, dentre outros (FEM, 2012; HALL et al., 2010). Em Economia, tais tratativas iniciaram através do estudo de Easterlin (1974), que relacionou, ao longo do tempo, a felicidade reportada pelas pessoas com a situação econômica dos EUA. Nesta perspectiva, o bem-estar individual pode ser reduzido a uma única dimensão: a felicidade. Então, se as pessoas estão felizes ou satisfeitas com suas vidas, isso é tudo o que importa para o seu bem-estar, sendo que qualquer outro atributo importante para a vida das pessoas como saúde, educação, finanças etc. deve ser avaliada na proporção que contribui para a felicidade das mesmas. O progresso, neste caso, ocorre quando há um aumento na felicidade ou satisfação média dos indivíduos (LAYARD, 2008).

32 A quinta proposta a citar é a de mensuração do desenvolvimento humano, tendo por quadro conceptual subjacente à abordagem das capacidades. 0 principal indicador nesta perspectiva é o Índice de Desenvolvimento Humano (IDH), criado 1990 pelos economistas Mahbub ul Haq e Amartya Sen. Para desenvolver o IDH, foram selecionadas apenas três dimensões consideradas essenciais para o bem-estar: saúde (expectativa de vida ao nascer), educação (escolaridade) e padrão de vida (PIB per capita) (ONU, 1990). Já no ano de 2000, outra iniciativa ganhou destaque com a Declaração do Milênio das Nações Unidas (AGNU, 2000), que posteriormente foi implementada através de relatórios anuais sobre os progressos alcançados pelos Estados-Membros da ONU em oito objetivos, orientados por mais de 60 indicadores, que devem ser atingidos até 2015 (AGNU, 2002; ONU, 2005).

O sexto e último modelo de avaliação da sociedade está relacionado a indicadores institucionais, que medem, em determinado país ou região, questões como governança, corrupção, democracia, direitos humanos, cultura e valores (SCRIVENS; IASIELLO, 2010). Este processo foi influenciado, a partir da década de 1990, pelo reconhecimento da necessidade de um bom governo para o melhor desempenho econômico e atração de investimentos. Também a corrente institucionalista em economia, principalmente o economista Douglas North, argumentou da necessidade de considerar o sistema de governança de um país e suas instituições formais e informais, para o crescimento econômico e o bem-estar das populações (ARNDT; OMAN, 2006). Neste sentido, surgiram iniciativas do Banco Mundial e da Transparência Internacional. 0 primeiro criou em 1996 o The Worldwide Governance Indicators, que mede seis dimensões de governança em mais de 200 países e territórios: voz e responsabilização, estabilidade política e ausência de violência ou terrorismo, eficácia do governo, qualidade regulatória, estado de direito e controle da corrupção (KAUFMANN; KRAAY; MASTRUZZI, 2010). O segundo desenvolveu o Corruption Perceptions Index, o qual mede os níveis percebidos de corrupção no setor público em 176 países de todo o mundo (TRANSPARENCY, 2012). Além disso, destaca-se o surgimento de pesquisas que medem 
as percepções dos indivíduos quanto a questões políticas, sociais, econômicas, institucionais, culturais, valores pessoais, entre outras. Este é o caso de institutos de pesquisa como o International Social Survey Programme, Latinobarometer, World Values Survey e outros.

34 Todas estas iniciativas possuem uma importância tácita em relação ao estudo do progresso, porque foram capazes de captar aspectos que são importantes aos indivíduos, de modo que algumas se tornaram mundialmente reconhecidas como meios de avaliar e comparar os países, principalmente o PIB e o IDH. Entretanto, a crítica que tem sido feita está relacionada ao fato de que tais indicadores representam apenas determinado âmbito do progresso, isto é, representavam parcialmente os aspectos concernentes ao bem-estar dos indivíduos. Ou seja, tal crítica é relativizada ao fato de que estes indicadores não podem ser analisados sozinhos, de modo que se faz importante avaliar o progresso através de uma abordagem mais abrangente, multidimensional, que leve em conta uma ampla gama de fatores importante às pessoas, questões estas que são expostas nas duas subseções subsequentes.

\section{MEDIDAS HODIERNAS DE PROGRESSO}

35 Conforme visto na seção anterior, uma crítica aos indicadores que tradicionalmente medem a situação da sociedade é o fato de eles perscrutarem apenas parte daquilo que importa para a vida das pessoas. As principais críticas estão relacionadas ao destaque que tem sido dado aos indicadores econômicos para aferir a sociedade, principalmente o PIB (cf. SEN, 2008; 2010; CCE, 2009; GOOSSENS et al., 2007; OCDE, 2011b; STIGLITZ; SEN; FITOUSSI, 2009).

36 De acordo com a OCDE (2011b, p. 14), “[...] concerns have emerged that standard macro-economic statistics, such as GDP, which for a long time had been used as proxies to measure well-being, failed to give a true account of people's current and future living conditions". Sen (2010) exemplifica esta situação ao demonstrar através de dados comparativos que, apesar do aumento da opulência no mundo, um grande número de pessoas não desfrutam de liberdades básicas. E mesmo em países ricos, há dissonância entre a situação de vida de diferentes grupos étnicos, como é o caso de brancos e negros nos Estados Unidos. Sen (2010) também se opõe a ideia de que o crescimento do PIB seja considerado um fim em si mesmo. Para ele, o essencial é a expansão das liberdades humanas. Por sua vez, Goossens et al. (2007) explicam que o PIB não leva em conta o que chama de crescimento ou desenvolvimento sustentável. Então, para ser possível medir progresso, riqueza e bem-estar, devem-se incorporar indicadores para complementar o PIB, indicadores estes que relacionem os custos e benefícios sociais e ambientais.

37 Assim, no século XXI, países e instituições têm trabalhado em projetos para aferição do progresso, os quais procuram captar a situação de vida atual e futura das pessoas, sem se limitar às condições materiais - como o PIB per capita -, mas incluindo questões como as aspirações dos indivíduos e a sustentabilidade das sociedades ao longo do tempo. Estes projetos podem ser encontrados em uma plataforma na Internet chamada Wikiprogress. Esta plataforma foi lançada no $3^{\circ}$ Fórum Mundial da OCDE, ocorrida em Outubro de 2009 na cidade de Busan, Coréia do Sul, e tem por objetivo compartilhar informações sobre iniciativas de avaliação do progresso ao redor do mundo. "Our goal is to create a web community around the vision of measuring the progress of societies 
by creating a place where progress and well-being data and research articles can be loaded, visualised, analysed and shared" (WIKIPROGRESS, 2013, p. 1).

Utilizando-se do Wikiprogress, foi possível acessar e consultar 50 projetos, os quais têm em comum o fato de buscarem fornecer uma ampla gama de dados sobre certa região, possibilitando análises diversificadas. Entretanto, são diversos os meios pelos quais os mesmos fazem isso e inúmeros os indicadores utilizados. Alguns fornecem formas criativas e rebuscadas de visualização dos dados, inclusive através de ferramentas de interação com os usuários e de visualização em mapas.

Todavia, para os objetivos o presente estudo, restringiu-se dos 50 projetos para apenas 14. Para chegar a este número, primeiramente foram selecionou aqueles que tinham por objetivo medir o progresso, a qualidade de vida ou o bem-estar das populações, e isto deveria ser feito através de uma abordagem multidimensional. Após isto, foram excluídos projetos que: (a) não estivessem disponíveis em português, inglês ou espanhol; (b) fossem restritos a análise de municípios ou regiões dentro de um país; (c) apresentassem um grande número de indicadores, mas sem objetivos específicos ou sem uma análise e estruturação dos dados em conjunto; (d) que fossem restritos a determinadas áreas, como no caso de alguns que eram referentes aos Objetivos do Milênio e; (e) apresentassem apenas intenções e discussões, sem possuírem, ainda, relatórios com análise do progresso a partir de indicadores. Na Tabela 1 são mostrados os projetos selecionados, na qual também há a quantidade de dimensões e de indicadores que constam em cada um destes.

Tabela - Projetos, dimensões e indicadores sobre o progresso

\begin{tabular}{llccl}
\hline \multicolumn{1}{c}{$\begin{array}{c}\text { País ou } \\
\text { Região }\end{array}$} & \multicolumn{1}{c}{ Projeto* $^{\text {Qtde. }}$} & $\begin{array}{c}\text { Qtde. } \\
\text { Dimen. }\end{array}$ & \multicolumn{1}{c}{ Fonte } \\
\hline África do Sul & South African Development Index & 6 & 25 & South African (2013) \\
Austrália & Measures of Australia's Progress & 17 & 69 & Commonwealth (2010) \\
Butão & Gross National Happiness & 9 & 33 & Ura et al (2012) \\
Canadá & Canadian Index of Wellbeing & 8 & 64 & Canadian (2012) \\
EUA & Gallup-Healthways & 6 & 25 & $\begin{array}{l}\text { Gallup e Healthways } \\
\text { (2018) }\end{array}$ \\
Hong Kong & The Centre for Quality of Life & 3 & 21 & Chinese (2012) \\
Irlanda & Measuring Ireland's Progress & 49 & 83 & Ireland (2012) \\
$\begin{array}{l}\text { Nova } \\
\text { Zelândia }\end{array}$ & Measuring New Zealand's Progress & 15 & 85 & Zealand (2009) \\
$\begin{array}{l}\text { Nova } \\
\text { Zelândia }\end{array}$ & Social Report & 10 & 43 & Zealand (2010) \\
OCDE & Better Life Index & 11 & 79 & OCDE (2011a, 2011b) \\
Reino Unido & Measuring National Wellbeing & 10 & 38 & Beaumont (2011, 2012) \\
Mundo & Social Progress Imperative & 12 & 52 & $\begin{array}{l}\text { Porter, Stern e Loría } \\
\text { (2013) }\end{array}$ \\
\hline Mundo & The Economist & 9 & 9 & Economist (2013) \\
Suíça & $\begin{array}{l}\text { Monitoring Sustainable } \\
\text { Development }\end{array}$ & 4 & 63 & Willi et al (2012) \\
\hline
\end{tabular}

Fonte: Wikiprogress, 2013

40 O total de indicadores dos projetos observados na Tabela 1 é de 689 , sendo que esta é apenas uma soma das quantidades, e não representa a quantidade real de indicadores caso não fossem contabilizados aqueles que se repetem em mais de um projeto, como, 
por exemplo, o indicador de desemprego, o qual se encontra na maioria. Além disso, para esta contagem, foram excluídos indicadores repetidos em um mesmo projeto, quer dizer, indicadores que eram replicados para fazer avaliações por gênero, idade, renda e sexo, por exemplo. Também foi contabilizado como dimensão o que em alguns projetos era chamado de domínio, utilizando-se como critério o fato de nesta pesquisa ser considerado como domínio o agregado de diversas dimensões, e cada uma destas como sendo determinado componente do progresso e que possui um ou mais indicadores que a representam. Sendo assim, em seguida é feita uma análise dos projetos, separados por grupos com características em comum.

41 Primeiramente, alguns destes projetos possuem um desenvolvimento ainda incipiente, no sentido de resumirem o progresso em um pequeno número de indicadores e por não apresentarem uma discussão detalhada sobre questões como a metodologia utilizada, a situação econômica e social da sociedade e a análise dos dados. Também apresentam o resultado da avaliação do progresso em relatórios resumidos (entre cinco e 12 páginas). Este é o caso da África do Sul (SOUTH, 2013), Hong Kong (CHINESE, 2012) e The Economist (ECONOMIST, 2013). Estes três projetos contribuem ao fornecerem indicadores para avaliar o progresso, que podem ser utilizados e comparados com os demais projetos, aumentando a base informacional.

42 Diferentemente dos anteriores, há três outros projetos que se destacam pelo número de indicadores e pela qualidade na apresentação e análises dos resultados e pela robustez dos relatórios, são eles Austrália (COMMONWEALTH, 2010), Irlanda (IRELAND, 2012), Suíça (WILLI et al., 2012) e os dois projetos da Nova Zelândia (ZEALAND, 2009; 2010). Os cinco possuem em comum a apresentação dos resultados através de gráficos e tabelas, e descrição de quais indicadores ou dimensões tem melhorado com o passar do tempo. A Irlanda faz comparações dos seus resultados em relação aos demais países de União Europeia. A Nova Zelândia busca analisar o progresso evidenciando indicadores de sustentabilidade na primeira referência, já na segunda destaca indicadores de ordem social. A Suíça exibe os resultados através de símbolos que ilustram as tendências objetivadas, as observadas e a avaliação entre o que era esperado e o corrido. E, dentre estes cincos, a Austrália faz uma análise mais aperfeiçoada de como selecionou as dimensões e os indicadores, sendo que apresenta também um benchmarking com projetos de outras partes do mundo (COMMONWEALTH, 2012). A problemática encontrada nestes projetos é o fato de não é utilizarem diversas variáveis que não representam o progresso em si, mas que são, em alguns casos, meios de fazer a sociedade progredir como, por exemplo, despesa com educação, fluxo de investimentos, taxa de câmbio etc. De qualquer modo, estes projetos fornecem contributo para análise do progresso numa perspectiva multidimensional e ampla.

43 Um terceiro grupo a tratar é formado por projetos que se diferenciam pela sua especificidade na escolha dos indicadores usados para avaliar o progresso, são eles: Butão (URA et al., 2012), Reino Unido (BEAUMONT, 2011; 2012) e Gallup (GALLUP; HEALTHWAYS, 2018). O Butão utiliza indicadores que são bastante particulares a sua cultura e valores. Porém, também possui indicadores que reconhecidos por outros projetos como importantes para o bem-estar dos indivíduos como qualidade da habitação, renda familiar, alfabetização, dentre outros. Já o Reino Unido dá maior relevância para bem-estar subjetivo, pois a maioria dos indicadores está relacionado com o relato dos indivíduos para questões sobre saúde, educação, uso do tempo, finanças etc. $O$ Gallup também tem a mesma particularidade, mas se destaca por tratar 
principalmente sobre aspectos da saúde física e emocional das pessoas. Estes três projetos sozinhos fornecem uma visão de progresso particularizada, mas juntos com os demais são capazes de enriquecer este trabalho ao apresentarem uma visão diferenciada dos meios e indicadores para avaliar o progresso, os quais também devem ser levados em conta.

O último grupo a ser apresentado, dos 14 selecionados, é formado por Canadá (CANADIAN, 2012), Social Progress Index (PORTER; STERN; LORÍA, 2013) e OCDE (2011a, 2011b). O destaque para estes três grupos é o formato inteligível, acessível e interativo no qual detalham o grau de progresso, o que pode ser conferido nos seus websites [www.uwaterloo.ca/canadian-index-wellbeing/; www.socialprogressimperative.org/; www.oecdbetterlifeindex.org/]. Estes três projetos também aparentam ser os mais avançados na escolha de uma abordagem multidimensional do progresso, bem como na forma que detalham os resultados. São contributos importantes neste estudo em termos de formatação e também em relação as dimensões e indicadores que utilizaram.

Por fim, a novidade destes projetos é o fato de buscarem avaliar a sociedade a partir de uma gama maior de informações e aspectos consoantes ao bem-estar dos indivíduos, isto é, compreender quais são os fatores que realmente importam na vida das pessoas. $O$ relatório do Fórum Econômico Mundial considera que "[i]f you treasure it, measure it" (FEM, 2012, p. 4), o que pode ser complementado adequadamente por Stiglitz, Sen e Fitoussi $(2009$, p. 7), ao afirmar que "what we measure affects what we do". Assim, medir e compreender aquilo que realmente repercute para o bem-estar e a felicidade das gerações atuais e futuras oferece um novo conjunto de prioridades que podem e devem ser apoiadas, seja pelos governos, pelas empresas ou mesmo no papel de agente de cada indivíduo (FEM, 2012). O ponto em comum entre esses diferentes projetos é o desejo de fazer algum tipo de avaliação multidimensional das condições e das mudanças sociais para além de um enfoque estritamente econômico.

\section{CONCLUSÃO}

Este artigo teve por objetivo fazer uma revisão histórica sobre a concepção de progresso, sendo dividido da seguinte forma. Na seção 2, foi explorada a ideia de progresso e como este é entendido com o passar do tempo e por diferentes autores. Logo em seguida, na seção 3, foi feito a conexão entre Progresso e Bem-Estar, de modo que aquele passa a ser entendido de acordo com este. Na seção 4 , houve a análise dos aportes teóricos sobre o bem-estar, os quais estão relacionados à diferentes abordagens econômicas e de justiça. Na seção 5 foram apresentadas diversas iniciativas de mensuração e análise do estado da sociedade e concernentes ao bem-estar dos indivíduos, as quais representam meios de verificar como a sociedade progrediu, mesmo que restrito a determinados âmbitos. Porém, logo em seguida, na seção 6, foram mostrados os novos estudos que visam avaliar o progresso através de uma perspectiva mais abrangente, envolvendo diversas dimensões e indicadores relativos ao bem-estar dos indivíduos. Também foram descritos e detalhados 14 projetos selecionados.

47 Assim, através deste estudo, foi possível oferecer um conjunto informacional histórico, teórico, conceitual e reflexivo que permeia a questão do progresso e sua relação com a temática do bem-estar. Porém, considera-se imprescindível que este debate persevere através de outras pesquisas, de modo que se alargue o entendimento sobre progresso econômico e social para que as problemáticas que persistem na sociedade sejam resolvidas em vistas de um futuro melhor. As ameaças ambientais, os problemas de 
saúde, a falta de confiança interpessoal, o desinteresse quanto às questões políticas, a marginalização de parte da população que sobrevive com parcos recursos, os problemas de saúde, o estresse, o trânsito caótico, a poluição das grandes cidades, são estes problemas, entre tantos outros, que devem ser enfrentados tanto por políticos e cidadãos, quanto pelos economistas. Sendo assim, faz-se necessário a busca por novos modelos de progresso, que encaminhem a sociedade a níveis mais elevados de bemestar, em que as pessoas portem não apenas os recursos necessários para a sobrevivência, mas também para uma existência saudável, feliz e com a liberdade de realizarem a vida que almejam.

\section{BIBLIOGRAFIA}

ABBAGNANO, Nicola. Dicionário de filosofia. São Paulo: Martins Fontes, 2000.

AGNU (Assembléia Geral das Nações Unidas). United Nations Millennium Declaration. Resoltion number A/RES/55/2. New York: 2000.

AGNU (Assembléia Geral das Nações Unidas). Implementation of the United Nations Millennium Declaration. Resoltion number A/57/270. New York: 2002.

ARNDT, Christiane; OMAN, Charles. Uses and Abuses of Governance Indicators. Pars: OCDE Development Centre Studies, 2006.

BEAUMONT, Jen. Measuring National Well-being: A discussion paper on domains and measures. Londres: Office for National Statistics, 2011.

BEAUMONT, Jen. Measuring National Well-being: Report on consultation responses on proposed domains and measures. Londres: Office for National Statistics, 2012.

BLANCHARD, Olivier Jean. Neoclassical Synthesis. In: DURLAUF, Steven N.; BLUME, Lawrence E. (Eds.). The New Palgrave Dictionary of Economics. Palgrave Macmillan, 2008.

BRUNI, Luigino; PORTA, Pier Luigi. Introduction. In: BRUNI, Luigino; PORTA, Pier Luigi (Eds.). Handbook on the Economics of Happiness. Cheltenham: Edward Elgar, 2007.

CANADIAN Index of Wellbeing. How are Canadians Really Doing? The 2012 CIW Report. Waterloo, Ontario: Canadian Index of Wellbeing and University of Waterloo, 2012.

CE (Comissão Europeia). Measuring progress towards a more sustainable Europe: Sustainable development indicators for the European Union - Data 1990-2005. Luxembourg: Office for Official Publications of the European Communities, 2005.

CCE (Comissão das Comunidades Europeias). O PIB e mais além: Medir o progresso num mundo em mudança. Comunicação da Comissão ao Conselho e ao Parlamento Europeu, $\operatorname{COM(2009)} 433$ final, Bruxelas, ago. 2009.

CE (Comissão Europeia). EUROPA 2020 Estratégia para um crescimento inteligente, sustentável e inclusivo. Comunicação da Comissão, $\operatorname{COM(2010)} 2020$ final, Bruxelas, mar. 2010.

CHINESE University of Hong Kong, The Hong Kong Quality of Life Index. Hong Kong: The Centre for Quality of Life, Hong Kong Institute of Asia-Pacific Studies, 2012. 
COBB, Clifford W.; RIXFORD, Craig. Lessons Learned from the History of Social Indicators. San Francisco, CA: Redefining Progress, 1998.

COLANDER, David. Complexity and the History of Economic Thought: Perspectives on the History of Economic Thought. London: Routledge, 2000.

COMMONWEALTH of Australia. 1370-0 - Measures of Australia's Progress. Austrália: Australian Bureau of Statistics, 2010.

COMMONWEALTH of Australia. Measures of Australia's Progress: aspirations for our nation: a conversation with australians about Progress. Austrália: Australian Bureau of Statistics, 2012.

CONCEIÇÃO, Pedro; BANDURA, Romina. Measuring Subjective Wellbeing: A Summary Review of the Literature. Working Papers/ Discussion Papers, Office of Development Studies, United Nations Development Programme (UNDP), Nova York, mai. 2008.

DIENER, Ed; SELIGMAN, Martin E.P. Beyond Money: Toward an Economy of Well-Being. Psychological Science in the Public Interest, v. 5, n. 1, p. 1-31, 2004.

DUNLAPA, Riley E. Trends in public opinion toward environmental issues: 1965-1990. Society \& Natural Resources: An International Journal, v. 4, n 3, p. 285-312, 1991.

DUPAS, Gilberto. O mito do progresso; ou o progresso como mito. São Paulo: Editora UNESP, 2006. DUPAS, Gilberto. Progresso: como mito ou ideologia. Caderno IHU Idéias, São Leopoldo, n. 77, p. 1-35, 2007.

EASTERLIN, Richard Ainley. Does Economic Growth Improve the Human Lot? In: DAVID, Paul; REDER, Melvin (Eds.). Nations and Households in Economic Growth: Essays in Honor of Moses Abramovitz. New York: Academic Press, 1974.

ECONOMIST, The. The Economist Intelligence Unit's quality-of-life index: The world in 2005. Disponível em: http://www.economist.com/media/pdf/QUALITY_OF_LIFE.pdf. Acesso em: 29 mai. 2013.

FEM (Fórum Econômico Mundial). Well-being and Global Success. World Economic Forum Global Agenda Council on Health \& Well-being, 2012.

FREY, Bruno S.; STUTZER, Alois. Happiness \& Economics: How the economy and institutions affect human well-being. Princeton, New Jersey: Princeton University Press, 2002.

GALLUP; HEALTHWAYS. Gallup-Healthways Well-Being ${ }^{\mathrm{TM}}$ Index: Methodology Report for Indexes. Disponível em: http://www.well-beingindex.com/. Acesso em: 10 fev. 2018.

GIANNETTI, Eduardo. Vícios privados, benefícios públicos?: a ética na riqueza das nações. São Paulo: Companhia das Letras, 2007.

GOOSSENS, Yanne et al. Alternative Progress Indicators to Gross Domestic Product (GDP) as a means towards Sustainable Development, Estudo n. IP/A/ENVI/ST/2007-10, doc. n. PE 385.672. Policy Department Economic and Scientific Policy, European Parliament, Bruxelas, 2007.

GRAHAM, Carol. Economics of happiness. In: DURLAUF, Steven N.; BLUME, Lawrence E. (Eds.). The New Palgrave Dictionary of Economics. 2. ed. Nova Iorque: Palgrave Macmillan, 2008.

HALL, Jon et al. A Framework to Measure the Progress of Societies, OECD Publishing, OECD Statistics Working Paper Series, n. 34, jul. 2010.

HUNT, E. K. História do Pensamento Econômico: Uma perspectiva critica. 2. ed. Rio de Janeiro: Elsevier, 2005.

IRELAND, Government of. Measuring Ireland's Progress. Dublin: Central Statistics Office, 2012. 
KAHNEMAN, Daniel; DIENER, Ed; SCHWARZ, Norbert (Eds.). Well-Being: The Foundations of Hedonic Psychology. New York: Russell Sage Foundation, 1999.

KAUFMANN, Daniel; KRAAY, Aart; MASTRUZZI, Massimo. The Worldwide Governance Indicators: Methodology and Analytical Issues. The World Bank, Policy Research Working Paper, n. 5430, set. 2010.

LAYARD, Richard. Felicidade: Lições de uma nova ciência. Rio de Janeiro: Best Seller, 2008.

MCGILLIVRAY, Mark. Human Well-being: Issues, Concepts and Measures. In: MCGILLIVRAY, Mark (ed.). Human Well-Being: Concept and Measurement. New York: Palgrave Macmillan, 2007.

NISBET, Robert A. História da idéia de progresso. Brasília: Editora Universidade de Brasília, 1980.

OCDE (Organização para a Cooperação e Desenvolvimento Econômico). OECD List of Social Indicators. Paris: OECD Publications, 1982.

OCDE (Organização para a Cooperação e Desenvolvimento Econômico). Environmental Indicators: A preliminary set. Paris: OECD Publications and Information Centre, 1991.

OCDE (Organização para a Cooperação e Desenvolvimento Econômico). Compendium of OECD well-being indicators. Paris: OECD Publishing, 2011a.

OCDE (Organização para a Cooperação e Desenvolvimento Econômico). How's Life?: Measuring Well-being. Paris: OECD Publishing, 2011b.

ONU (Organização das Nações Unidas). Toward a System of Social and Demographic Statistics. Nova York: Departament of Economic and Social Affair, Statistical Office, Series F, No. 18, 1975.

ONU (Organização das Nações Unidas). Framework for the Development of Environment Statistics. Nova York: Departament of Economic and Social Affair, Statistical Office, Series M, No. $78,1984$.

ONU (Organização das Nações Unidas). Human Development Report 1990: Concept and Measurement of Human Development. Nova York: Programa das Nações Unidas para o Desenvolvimento, 1990.

ONU (Organização das Nações Unidas). The Millennium Development Goals Report 2005. Nova York: 2005.

OUTHWAITE, William, BOTTOMORE, Tom. Dicionário do pensamento social do Século XX. Rio de Janeiro: Jorge Zahar Ed., 1996.

PERLMAN, Mark; MCCANN JR, Charles R. The Pillars of Economic Understanding: Ideas and Traditions. Ann Arbor: University of Michigan Press, 1998.

PINTÉR, László; HARDI, Peter; BARTELMUS, Peter. Sustainable Development Indicators: Proposals for a Way Forward. Prepared for the United Nations Division for Sustainable Development (UNDSD). Nova York: International Institute for Sustainable Development, 2005.

PORTER, Michael E.; STERN, Scott; LORÍA, Roberto Artavia. Social Progress Index 2013.

Washington, DC: Social Progress Imperative, 2013.

ROBEYNS, Ingrid. The Capability Approach: a theoretical survey. Journal of Human Development, v. 6, n. 1, p. 93-114, mar. 2005.

ROBEYNS, Ingrid. The Capability Approach. In: ZALTA, Edward N.; NODELMAN, Uri; ALLEN, Colin (Eds.). The Stanford Encyclopedia of Philosophy. Summer $2011 \mathrm{ed}$. Stanford, CA: The Metaphysics Research Lab at Stanford University, 2011. 
SACHES, Jeffrey. Introduction. In: HELLIWELL, John; LAYARD, Richard; SACHS, Jeffrey (Eds.). World Happiness Report. New York: Earth Institute, Columbia University, 2012

SANDRONI, Paulo. Novíssimo Dicionário de Economia: A mais completa obra sobra o assunto já publicada no Brasil. 13. ed. São Paulo: Editora Best Seller, 2004.

SCRIVENS, Katherine; IASIELLO, Barbara. Indicators of "Societal Progress": lessons from international experiences, OECD Publishing, OECD Statistics Working Paper Series, n. 33, mai. 2010.

SEN, Amartya. Desigualdade reexaminada. Rio de Janeiro: Record, 2008.

SEN, Amartya. Desenvolvimento como Liberdade. São Paulo: Companhia das Letras, 2010.

SOUTH African Institute of Race Relations. South African Development Index (SADI): Fourth update for 2011. Disponível em: http://www.sairr.org.za/services/development-projects/SADI. Acesso em: 31 mai. 2013.

STIGLITZ, Joseph E.; SEN, Amartya; FITOUSSI, Jean-Paul. Report by the Commission on the Measurement of Economic Performance and Social Progress. The Commission, Paris: 2009.

TRANSPARENCY. International Corruption Perceptions Index 2012. Berlin: 2012.

TREWIN, Dennis; HALL, Jon. Developing Societal Progress Indicators: a practical guide, OECD Publishing, OECD Statistics Working Paper Series, n. 35, nov. 2010.

URA, Karma et al. A Short Guide to Gross National Happiness Index. Thimphu, Bhutan: The Centre for Bhutan Studies, 2012.

WIKIPROGRESS. Wikiprogress Annual Report 2012: Increasing Participation in Well-Being and Progress. Abr. 2013.

WILLI, Vincent et al. Sustainable Development Report 2012. Neuchâtel: Federal Statistical Office FSO, 2012

WWF (World Wide Fund for Nature). Global Footprint Network 2006. Switzerland: 2006.

ZEALAND, Statistics New. Measuring New Zealand's Progress Using a Sustainable Development Approach: 2008. Wellington: 2009.

ZEALAND, Government New. The Social Report: te purongo oranga tangata 2010. New Zealand: Ministry of Social Development, 2010.

\section{RESUMOS}

Em diversos países do mundo tem ocorrido uma busca por novos modelos de avaliação do progresso econômico e social. Apesar do crescimento econômico ser importante, novas prioridades são necessárias para as sociedades atingirem níveis mais elevados de bem-estar. Este artigo tem por objetivo fazer uma revisão bibliográfica sobre os conceitos de progresso e de bemestar através de uma perspectiva historiográfica e econômica. Também procura analisar quais são as medidas econômicas, sociais, ambientais, ou mesmo multidimensionais, utilizadas para avaliação da situação da sociedade ou de certa região. Tal discussão é apresentada de modo cronológico e conceitual. Inicialmente são explorados os conceitos, começando pelo constructo Progresso para em seguida tratar de Bem-Estar. Por último, são analisadas as medidas tradicionais e hodiernas do progresso. 
In several countries of the world there has been a search for new models for assessing economic and social progress. Although economic growth is important, new priorities are needed for societies to achieve higher levels of well-being. This article aims to make a bibliographic review on the concepts of progress and well-being through a historiographical and economic perspective. It also seeks to analyze what are the economic, social, environmental, or even multidimensional measures used to assess the situation of society or a certain region. Such discussion is presented chronologically and conceptually. Initially, the concepts are explored, starting with the Progress construct, and then dealing with Well-being. Finally, traditional and today's measures of progress are analyzed.

En diversos países del mundo ha ocurrido una búsqueda por nuevos modelos de evaluación del progreso económico y social. A pesar de que el crecimiento económico es importante, nuevas prioridades son necesarias para que las sociedades alcancen niveles más altos de bienestar. Este artículo tiene por objetivo hacer una revisión bibliográfica sobre los conceptos de progreso y de bienestar mediante una perspectiva historiográfica y económica. También busca analizar cuáles son las medidas económicas, sociales, ambientales y multidimensionales utilizadas para evaluar la situación de la sociedad o de una determinada región. Tal discusión se presenta de modo cronológico y conceptual. Inicialmente se exploran los conceptos, empezando por el constructo Progreso, para luego tratar del Bienestar. Por último, se analizan las medidas tradicionales y las etapas del progreso.

Dans plusieurs pays du monde, il y a eu une recherche de nouveaux modèles pour évaluer le progrès économique et social. Si la croissance économique est importante, de nouvelles priorités sont nécessaires pour que les sociétés atteignent des niveaux plus élevés de bien-être. Cet article vise à faire une revue bibliographique sur les concepts de progrès et de bien-être dans une perspective historiographique et économique. Il cherche également à analyser quelles sont les mesures économiques, sociales, environnementales, voire multidimensionnelles utilisées pour évaluer la situation de la société ou d'une certaine région. Cette discussion est présentée de manière chronologique et conceptuelle. Dans un premier temps, les concepts sont explorés, en commençant par la construction Progress, puis en traitant du bien-être. Enfin, les mesures traditionnelles et modernes du progrès sont analysées.

\section{ÍNDICE}

Palavras-chave: progresso; progresso social; bem-estar, indicadores sociais, políticas públicas

Palabras claves: Progreso; progreso social; bienestar, indicadores sociales, políticas públicas.

Keywords: progress; social progress; well-being, social indicators, public policies

Mots-clés: progrès; progrès social; bien-être, indicateurs sociaux, politiques publiques

\section{AUTOR}

\section{PEDRO HENRIQUE DE MORAIS CAMPETTI}

Mestre em Economia pela Unisinos. Professor de Economia no Instituto Federal do Rio Grande do Sul. E-mail: pedro.campetti@bento.ifrs.edu.br 